\title{
Эффекты согласования мод при стабилизации верхней границы сканирования в волоконном лазере с самосканированием частоты
}

\author{
$\underline{\text { А.Ю. Ткаченко }}^{1, *}$, И.А. Лобач ${ }^{1,2}$, Е.В. Подивилов ${ }^{1,2}$, С.И. Каблуков ${ }^{1,2}$ \\ ${ }^{1}$ Институт автоматики и электрометрии СО РАН \\ ${ }^{2}$ Новосибирский государственный университет \\ *E-mail: alinka.tkacenko@yandex.ru
}

DOI:10.31868/RFL2018.195-196

Перестраиваемые лазеры находят свое применение во многих областях науки и техники. Волоконные лазеры, в которых перестройка лазерной частоты происходит без добавления специальных перестраиваемых элементов, называют самосканирующими. Эффект самоиндуцированного сканирования частоты основан на формировании динамической обратной связи в активной середе [1]. Достаточно простая схема подобных лазеров позволяет им конкурировать с другими перестраиваемыми источниками в ряде приложений (например, см. [2]). Одной из важных характеристик самосканирующих лазеров является диапазон сканирования определяемый как разность между максимальным и минимальным значением длины волны в процессе одного сканирования. Для практических применений лазеров важны как значение диапазона сканирования, так и стабильность границ перестройки. В работе [3] было показано, что добавление в схему самосканирующего лазера отражателя Майкельсона на основе волоконной брэгговской решетки (ВБР) позволяет существенно уменьшить флуктуации как начальной, так и конечной границы сканирования в зависимости от длины волны ВБР. Коротковолновая ВБР позволяет определить начальное значение длины волны сканирования. Длинноволновая ВБР вынуждает начинать процесс сканирования заново. Однако вопрос механизма этого воздействия пока остается открытым. Данная работа посвящена комплексному изучению влияния параметров отражателя Майкельсона на стабильность конечной длины волны.
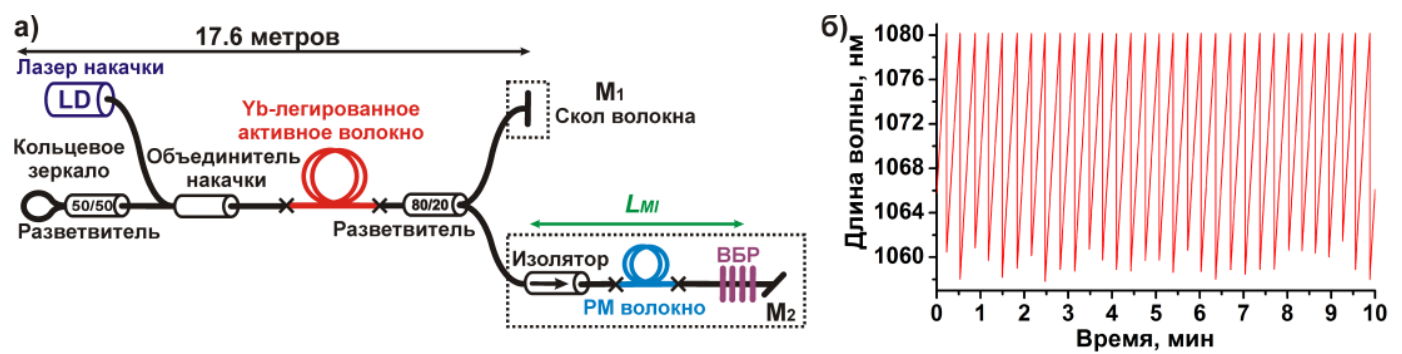

Рис.1. (а) Схема волоконного самосканирующего лазера с отражателем Майкельсона и (б) его характерная динамика спектра.

В работе исследовался волоконный самосканирующий иттербиевый лазер на основе компонент с сохранением поляризации. Активная среда на основе иттербиевого волокна с двойной оболочкой длиной 3 метра накачивалась лазерным диодом с длиной волны $~ 970$ нм. Резонатор лазера был образован широкополосным высокоотражающим кольцевым зеркалом и выходным отражателем на основе интерферометра Майкельсона. Отражатель Майкельсона образован 20/80 разветвителем и зеркалами $\mathrm{M}_{1}$ в виде прямого скола волокна и $\mathrm{M}_{2}$ в виде термостабилизированной высокоотражающей ВБР с резонансной длиной волны 1080 нм. Также зеркало $\mathrm{M}_{2}$ содержало в себе изолятор для существенного уменьшения 
уровня отражения от ВБР. В отсутствии ВБР лазер перестраивается в диапазоне от 1058 до 1081 нм с флуктуацией верхней границы порядка 100 пм [3]. Разность плеч интерферометра $L_{M I}$ варьировалась с помощью дополнительного куска одномодового волокна от 2 до 38 метров. В экспериментах измерялась долговременная динамика спектра генерации (см, например, Рис.1б) при различных разностях длин плеч интерферометра. Набор наблюдавшихся в эксперименте значений верхней границы сканирования в зависимости от разности плеч отражателя $L_{M I}$ представлены на Рис.2а. Также на Рис.2б представлен спектр отражения используемой ВБР. На Рис.2а можно выделить три характерные зоны $-A, B$ и $C$. В зонах $A$ происходит стабилизация длинноволновой границы сканирования по коротковолновому краю спектра отражения ВБР. В зонах $B$ наблюдается проскок сканирования через полосу отражения ВБР. В этом случае ситуация аналогична самосканированию частоты в лазере без ВБР. В зоне $C$ в отличие от зоны $A$ привязка осуществляется на коротковолновых боковых резонансах ВБР.

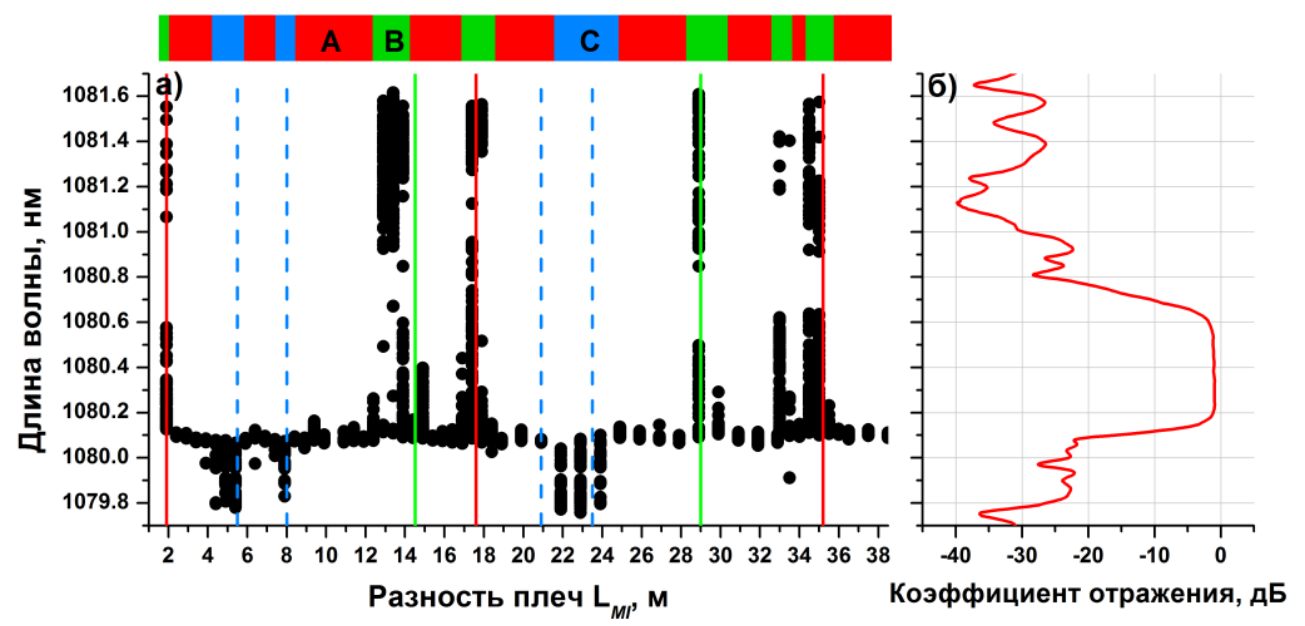

Рис.2. (а) Зависимость значений верхней границы сканирования от разности плеч интерферометра. (б) Спектр отражения используемой ВБР.

Было замечено, что зоны $B$ наблюдаются в узких (2-3 метра) областях разности плеч $L_{M I}$, что свидетельствует о резонансном механизме процесса. В частности, в некоторых зонах $B$ проскок сканирования происходит при разности плеч кратной полной длине резонатора 17.6 м (красные сплошные линии на Рис. 2a). Аналогичный результат был указан в работе [3]. Однако можно заметить, что аналогичные линии есть и на длинах кратных $\sim 14.5$ м (красные сплошные линии на Рис. 2a), что может свидетельствовать о наличии в лазере более короткого резонатора. Можно предположить, что этот резонанс связан с резонатором сформированный плотным зеркалом и динамической решеткой. Зоны $C$ (синие пунктирные линии на Рис. 2а) наблюдаются на длинах кратных половинам указанных резонаторов.

Более детальное описание экспериментов по изучению стабильности верхней границы сканирования при варьировании параметров интерферометра, а также моделирования резонансных эффектов будет представлено в докладе.

Работа выполнена при финансовой поддержке РНФ (грант 18-12-00243).

\section{Литература}

[1] I.A. Lobach et al, Laser Phys. Lett. 11,045103 (2014)

[2] A.Yu. Tkachenko et al, Opt. Express 25, 17600 (2017)

[3] A.Yu. Tkachenko et al, Opt. Lett. 43, 1558-1561, (2018) 